\title{
AN UNUSUAL CASE OF ADENOLYMPHOMA OF THE PAROTID GLAND
}

\author{
By H. J. Hambury, M.D., F.R.C.S., and J. L. Williams, M.B., B.S. \\ Fulham Hospital, London
}

Adenolymphoma of the salivary glands would still appear to be rare enough to warrant a report of its occurrence, particularly if a case presents unusual features.

\section{Case Report}

H.A., aged 70, attended the Surgical Outpatients' Department at Fulham Hospital in 1948, with a large painless swelling in the left parotid region which had gradually increased in size since he had noticed it first about 1943. He declined operative treatment.

In March 195 I he attended again, for a strangulated right femoral hernia, and agreed during convalescence to have the tumour aspirated as it had grown considerably (Fig. 3). A greenish mucilaginous material was obtained. This continued to issue from the puncture wound and a mild infection occurred which caused sufficient discomfort to make him request removal of the tumour.

On examination the swelling in the region of the left mandibular angle was about $10: 8: 8 \mathrm{~cm}$. in size, hemispherical and somewhat pendulous, with a smaller similar lump close above the upper pole. The tumours were uniformly soft, smooth and, in large parts, fluctuant. They were mobile in all directions. They were not attached to the overlying skin, nor obviously to bone or underlying soft tissues. They were superficial to the sternomastoid muscle. The large tumour was moderately tender, but after a course of antibiotic treatment the tenderness disappeared. There was a black, sharply limited pit in the skin beneath the ear which looked like a punctum. Based upon site, softness and fluctuation,

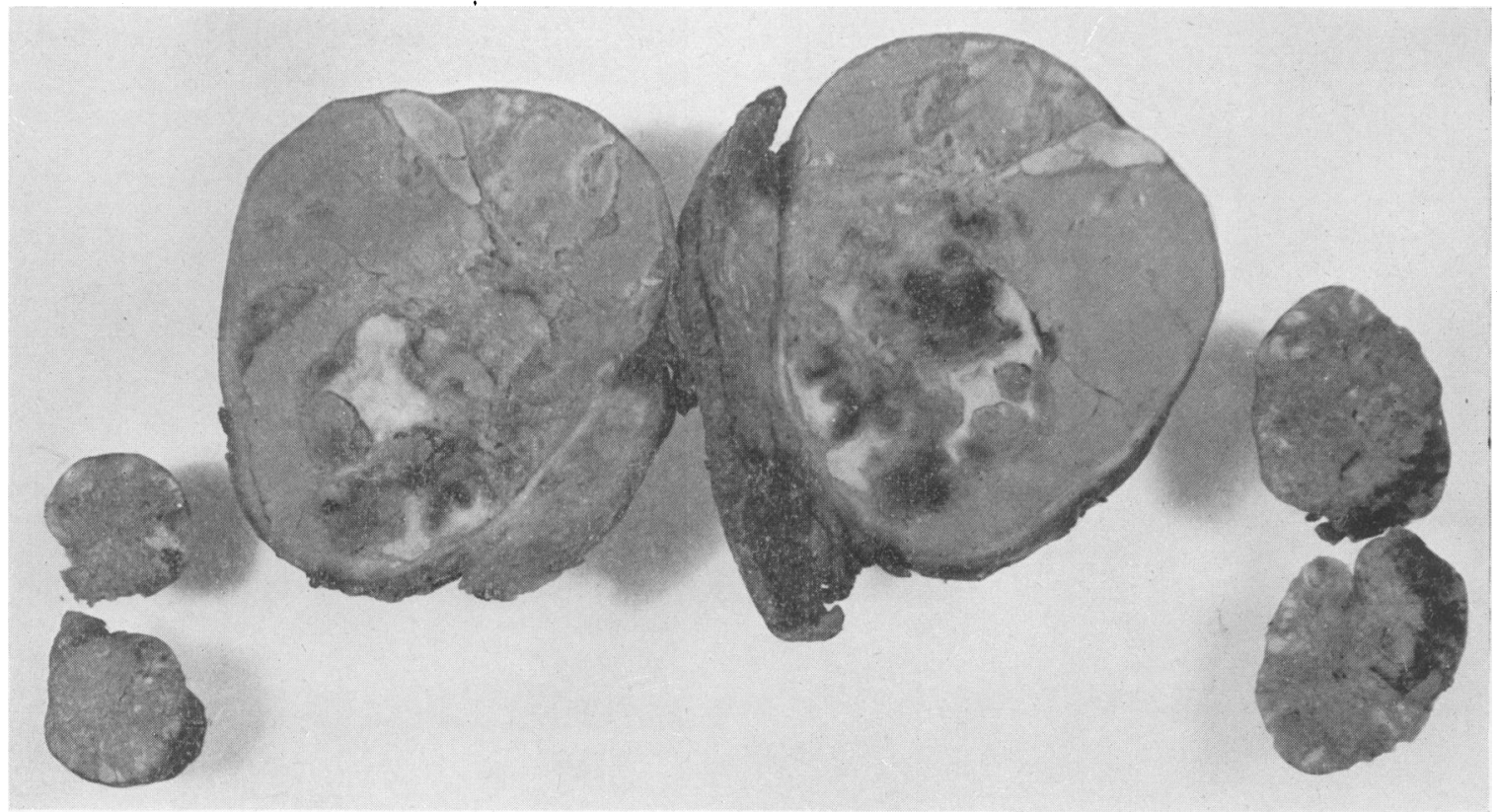

FIG. I 


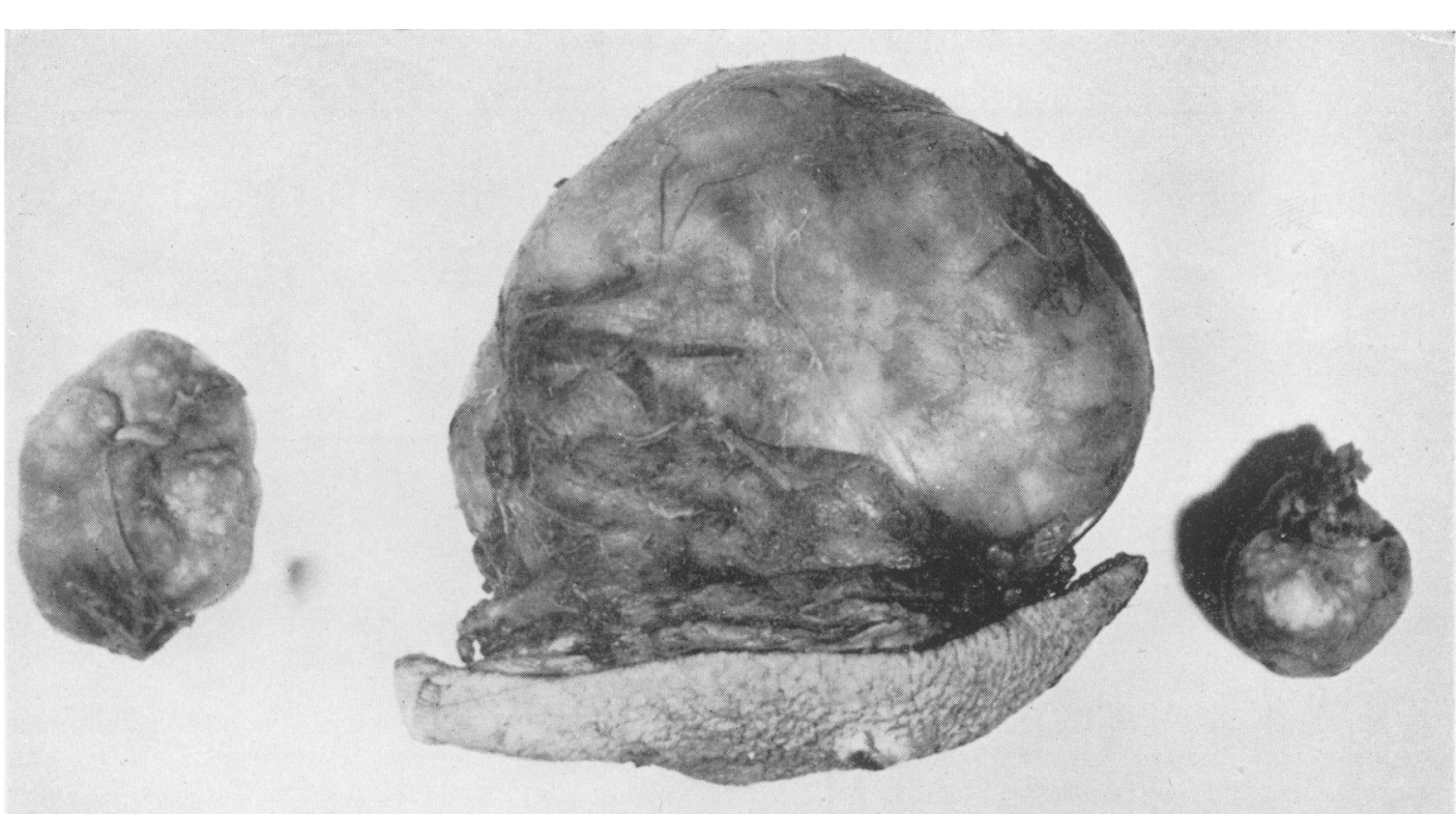

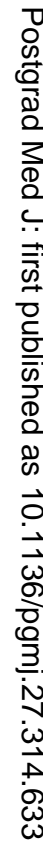

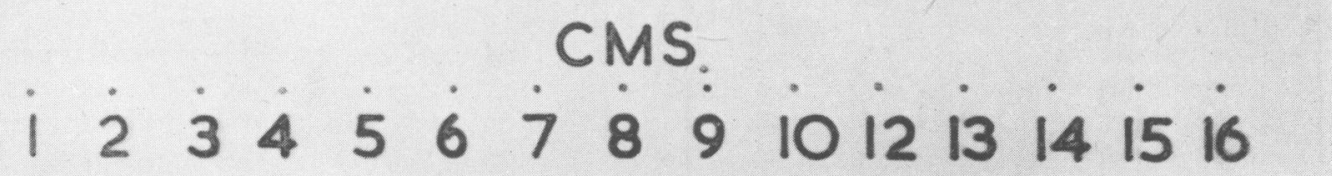

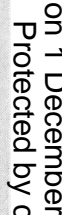

FIG. 2
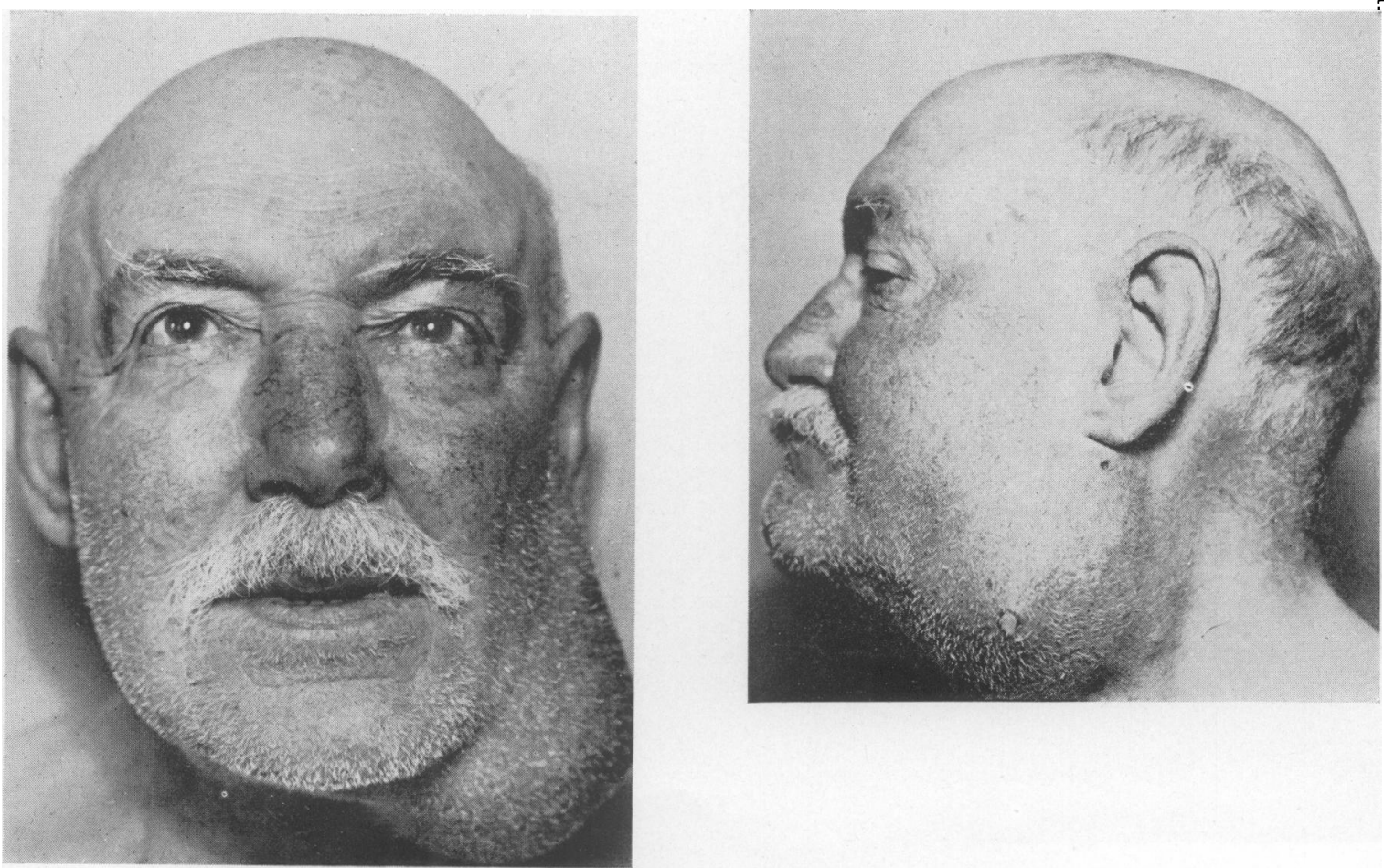

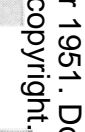



FIG. 3 
mobility and the peculiar discharge, the diagnosis of adenolymphoma of the parotid was made preoperatively. The lack of skin attachment ruled out a sebaceous cyst, as well as the mucilaginous nature of the discharge. The relationship to the sternomastoid and the presence of firm areas alternating with fluctuation ruled out a branchial cyst, as well as the age of the patient, albeit that we have only recently removed a branchial cyst which had appeared at the age of 54 years. Mixed parotid tumours are firmer, have only occasionally small areas of fluctuation and have a nodular surface, as opposed to the characteristically smooth surface observed here. A carotid body tumour would have been in the line of the large vessels, mobile from side to side only, and would have shown expansile or transmitted pulsation.

On June 8, I95I, the mass was removed through an incision in the direction of Langer's lines, enclosing an attenuated ellipse of redundant skin and the black skin pit above. There were one large and two smaller tumours (Figs. I and 2) which shelled out easily along a comfortable line of cleavage. The smaller tumours in particular were clearly embedded in parotid substance; one of these was quite separate and might have easily been overlooked, thus giving rise to a recurrence. The patient made an uneventful recovery, except for a transient weakness in the area of distribution of the cervical branch of the left facial nerve.

The histological examination of the tumour demonstrated a degenerate adenolymphoma (Fig. 4). Adenolymphomas consist of cystic spaces of varying size lined by columnar celled epithelium, with nuclei nearest to the cystic space. Under high power magnification one can distinguish within the epithelium the so-called 'onkocytes' staining deeply with eosin which, however, are no longer regarded as characteristic of adenolymphoma alone. The tumour stroma is filled with densely packed lymphoid cells, devoid of sinuses. This combination of glandular tissue



FIG. 4.-Histological section showing cystic spaces lined with columnar-celled multilayered epithelium, with nuclei nearest to cystic space. Tumour stroma filled with densely packed lymphoid cells. Haematoxilin-Eosin $\times 130$. 
with a lymphoid matrix makes the designation adenolymphoma the most fitting.

When seen during follow up studies, the patient was free from any suggestion of recurrence. The few instances of malignant changes reported in the literature are of dubious significance. Provided the operative exploration has been thorough, and satellite tumours are removed, there should be no recurrence.

\section{Comments}

Amongst the 128 cases reported until recently (Hevenor et al., 1950), this case is noteworthy because of the unusual size of one of the tumours, viz. Io: $8: 8 \mathrm{~cm}$. Only three cases of multiple tumours have been reported (Ramage et al., 1943; Martin et al., 1944), the case under review being the fourth. In I 935 Carmichael et al. knew of no one case correctly diagnosed pre-operatively, but the well-marked characteristics exemplified in this case should really afford the means for a clinical diagnosis.

Our thanks are due to $\mathrm{Mr}$. H. L. Cochrane, F.R.C.S., under whose care the patient was admitted, for permission to publish this report, and to Dr. M. Gillespie, M.D., for the histological examination.

\section{BIBLIOGRAPHY}

CARMICHAEL, R., DAVIE, T. B., and STEWART, M. J. (1935), F. Path. and Bact., 40, 601.

HEVENOR, E. P., and CLARK, C. E. (1950), Surg. Gynec. and Obstetrics, 90, 746 .

MARTIN, H., and EHRLICH, H. E. (1944), Ibid., 79, 6I I.

RAMAGE, J. S., BINNIE, G. G., and MCCALL, A. I. (1943), Brit. F. Surgery, 31, 189.


An Address Book for the Medical profession, showing how to reach the various Colleges, Societies, Institutes and Hospitals in and near London. Third edition: 1950.

Published by the

FELLOWSHIP OF POSTGRADUATE MEDICINE

60 Portland Place, London, W. I

Price 2s. 6d.

Specimen entry :

FELLOWSHIP OF POSTGRADUATE MEDICINE, 60 Portland Place, London, W.r

Tel. : Langham 4266.

Nearest Underground Railway Stations: Oxford Circus; Regents Park; Great Portland Street; thence 5 minutes' walk.

Omnibuses running near: $6,13,15,60,7,8,25,73$, 1 2, 88, 23, 59a, I 59, alight Oxford Circus, thence 5 minutes' walk; $137,3,53 \mathrm{a}$, alight Oxford Circus or Great Portland Street, thence 5 minutes' walk.

Green Line Coaches: 709, 710, 711, 715, alight Portland Place, thence 2 minutes' walk. 